\title{
Compassion Fatigue in Cancer Nursing: Limiting the Emotional Cost of Caring
}

\author{
Adaobi Lilian Obiekwu ${ }^{1 *}$, Chiamaka Jennifer Okafor ${ }^{2}$ and Ngozi Joy Omotola ${ }^{3}$ \\ ${ }^{1,2,3}$ Department of Nursing Sciences, Faculty of Health Sciences and Technology, University of Nigeria \\ Enugu Campus, Enugu State, Nigeria \\ *Corresponding author's email: ada.obiekwu [AT] unn.edu.ng
}

\begin{abstract}
A diagnosis of cancer is overly devastating to patients and their significant others, creating a tsunami of emotions, pain and suffering, with oncology nurses as focal point in the cancer tragedy. With the increasing burden of cancer, nurses in the field of oncology witness profound suffering while providing compassionate care. Providing compassionate care is satisfying but a point reaches where nurses' may experience a diminution in compassionate ability, a state referred to as compassion fatigue. A state which has consequences not only for nurses themselves, but also for patient care and organizations' productivity. While individual nurses should pay attention to self-care in order to protect themselves from compassion fatigue; nurse managers and hospital administrators should support them by creating a favourable workplace. Institutional strategies to prevent compassion fatigue include acknowledgement of existence of the phenomenon, education on coping strategies, on-site counselling services and fostering peer support.
\end{abstract}

Keywords--- compassion fatigue, cancer nursing, emotional distress

\section{INTRODUCTION}

According to the International Agency for Research on Cancer (IARC), about 18.1 million people developed cancer in 2018 worldwide, with 9.6 million deaths and 43.8 million people living with cancer within 5 years of diagnosis. ${ }^{\text {[1] }}$ This rising trend is attributed to population growth, ageing and changes in lifestyle associated with socio-economic development. ${ }^{[1]}$

A diagnosis of cancer is overly devastating to patients and their significant others, creating a tsunami of emotions, pain and suffering, with oncology nurses as focal point in the cancer tragedy. With the increasing burden of cancer due to improvement in diagnostic and management techniques, nurses working in the field of oncology experience profound stress both physically and emotionally. ${ }^{[2]}$

Nursing only occurs within interpersonal relationships with caring, empathy and compassion as core principles. Caring has been described as the foundational value, origin and essence of Nursing. Also, empirical studies show that amongst other services provided by nurses, human care, kindness, empathy and concern were perceived as the most important caring behaviour by patients. ${ }^{[3]}$ Hence, it is expected of the nurse to be empathic, caring and compassionate at all times; to support patients, their families and significant others and equally respond to their changing needs.

Compassion is a deep awareness of the suffering of another with a desire to alleviate it. ${ }^{[4]}$ It has been noted as the noblest of all qualities of a human heart of which kindness, empathy, generosity and acceptance in response to pain and suffering of others are key manifestations. ${ }^{[4]}$ It is this compassion that often drive nurses to invest their emotions while patiently listening to patients' stories of sadness and despair arising from their illness and with these come emotional distress which may either be manifested or suppressed. The longer the nurse is exposed to patient's suffering, the more involved the nurse becomes and the more difficult it is to have clear professional boundaries, the nurse taking on patient's pain and suffering. Evidence from literatures suggest that engaging cancer patients compassionately is extremely rewarding and contributes to job satisfaction, positive self-esteem and feeling of social usefulness. ${ }^{[5]}$ Yet, supporting patients through their pain and suffering no matter how satisfying can mask the nurse-patient boundaries, leaving nurses at risk for negative emotional or physical outcome and compassion fatigue. ${ }^{(6,7,8)}$ This is referred to as the "cost to caring". [9]

Despite these known negative effects of caring and compassion on nurses in general and oncology nurses in particular, Vachon, Huggard and Huggard, noted that opportunities for venting emotions are still lacking; time for grieving patients death remain insufficient and resources to assist nurses cope with job-related stress are either inadequate or non-existent. ${ }^{[10]}$ Therefore, compassion stress, emotional distress, empathic strain and sorrow are neither detected early nor adequately managed, thus placing patient care at risk. 
Owing to the negative effects compassion fatigue has on the caring ability of the nurse and nurses' professional quality of life, it is essential that individual nurses, nurse managers, employers and organizations acknowledge the existence of this emotional burden and take bold steps for prevention and healing. However, little attention has been paid to prevention and treatment of compassion fatigue in oncology nurses especially in settings where majority of nurses are unaware of the concept. This makes it important that this phenomenon is discussed and strategies for self-care and institutional prevention and management highlighted.

\section{CONCEPT OF COMPASSION FATIGUE}

Compassion fatigue is a kind of secondary stress, an occupational hazard for those in the helping profession especially those expressing high degree of empathy. ${ }^{[11]}$ The term was coined by Joinson in 1992 while studying burnout in emergency room nurses, it is ambiguous and may often be misinterpreted with other kinds of work-related stress. ${ }^{[2]}$ It was originally used in the context of mental health counsellors working with trauma victims but is now generally applicable to many other helping professions. Although it has been referred to by Figley, one of the pioneer theorists as secondary traumatic stress [11]; Nolte et al. noted that compassion fatigue is a preferred term as it reflects a process occurring over time rather than as a result of a single distressing event. ${ }^{[2]}$ Compassion fatigue as described by Figley is a state of exhaustion and dysfunction, psychologically and socially as a result of prolonged exposure to compassion stress and all it invokes. ${ }^{[11]}$

Coetzee and Klopper defined it as "the final result of progressive and cumulative process that is caused by prolonged, continuous and intense contact with patients, the use of self and the exposure to stress" (p.237). ${ }^{\text {[13] }}$

Nolte et al. defined it as a state of exhaustion which limits the ability to engage in caring relationships and is a crucial component that impacts on professional nursing performance. ${ }^{[2]}$

It refers to the disengagement of caregivers from their patients which culminates with a reduction or inability to feel empathy or compassion towards patients and an inability to provide the patient care that is inappropriate. ${ }^{[14]}$

For the purpose of this review therefore, compassion fatigue is the weariness and diminution of the compassionate ability of a nurse arising from repeated experience of pain and suffering of others in a caring relationship. This simply means that the caring relationship between the caregiver and recipient may lack the lustre of compassion as the caregiver is repeatedly wearied with difficulties and trauma experienced by patients. As described by Figley, compassion fatigue develops in helping professions where professional who not directly exposed to trauma/suffering often hear stories of others' suffering, feel empathy for them and begin to experience their fears. ${ }^{[11]}$ These workers eventually lose a certain spark of optimism, their enthusiasm begins to dwindle, they tire and lose themselves in the compassionate caring relationship; they are not actually ill but they are not themselves.

Compassion fatigue progresses from a state of compassion discomfort to compassion stress and finally to compassion fatigue. ${ }^{[13]}$ If this is not effaced in early stages of compassion discomfort or compassion stress, the compassion ability of the nurse to others' pain and suffering may be permanently altered. ${ }^{[13]}$ A nurse who develops compassion fatigue often has an unwavering sense of duty for relieving the distress of those they help coupled with a feeling of powerlessness to separate themselves from the experience of the patients. They may later begin to distance themselves from the patients but continue to provide day to day care. Thus caregiving becomes inefficient as the caregiver may begin to lose compassion and become perfunctory. In the light of the above conceptualization of compassion fatigue, Fernando and Consedine while proposing the transactional model of physician's compassion argued that the term limits the compassionate ability of the caregiver as it depicts a depletion of compassion reservoir with use or over use. ${ }^{[15]}$ However, Valent had introduced an interactional model stating that a caregiver exposed to emotional stress cognitively appraises the situation and exhibits an adaptive or maladaptive response to stress. ${ }^{[16]}$ The direction of response is notably dependent on the emotional wherewithal of the caregiver. This shows that compassion fatigue is not necessarily an emptying of the compassion reservoire but depends on the response of the caregiver to secondary stress (sufferings and pain of patients), if it is effectively countered at the level of compassion discomfort or compassion stress, compassion fatigue will be prevented. Boyle further argued that compassion fatigue occurs when the compassion energy expended by healthcare providers with their patients is greater than the ability to recover from such energy loss therefore resulting to negative psychological and emotional consequences. [9] Arguments on the possibility of a finite nature of compassion is still ongoing and is subject to further investigation. Nevertheless, fact remains that chronic exposure to difficulties of patients bring emotional distress to the caregivers.

On the opposite end of compassion fatigue is compassion satisfaction. While compassion fatigue is the negative consequence of working with those experiencing suffering, compassion satisfaction is positive consequence, bringing a sense of gratification to those caring for others. ${ }^{[17]}$ Available evidence suggests that compassion satisfaction is an important part of the whole, thus increasing the significance of building resiliency and the transformation from negative to positive 
aspects. ${ }^{[17]}$ Collins and Long acknowledged that compassion satisfaction is an essential component in achieving work-life balance and self - actualization. ${ }^{[18]}$ Caregivers' motivation to help is shaped in part by the satisfaction derived from the work of helping others. When caregivers observe an improvement in the quality of life of the patients/clients they are serving, they are fulfilled and are motivated to do more. ${ }^{[19]}$ It has been posited that Compassion satisfaction assists caregivers to manage stress and contributes to feelings of self-value and self-worth when helping others. ${ }^{[20]}$ Compassion satisfaction also serves as a protector of the mental health of the workers. However, the relationship between compassion satisfaction and compassion fatigue is not fully understood as compassion satisfaction may coexist with compassion fatigue. As the symptoms progress, the compassion fatigue may become overwhelming leading to ineffective response to one supposed to be nurtured. ${ }^{[21,22]}$

Compassion fatigue and burnout are closely linked and sometimes confused. While compassion fatigue deals majorly with the relational nature of the condition, environmental stressors contribute greatly to burnout. ${ }^{[23]}$ Burnout can be experienced by professionals in a variety of work environment without exposure to vicarious trauma. ${ }^{[24]}$ Figley also noted that the onset of compassion fatigue is sudden while burnout gradually wears out the caregiver ${ }^{[11]}$ Coles further stated that burnout can

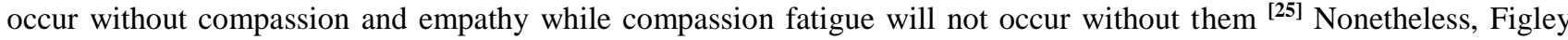
further stated that burnout is a predisposing factor to compassion fatigue together with secondary traumatic stress disorder. [11]

Oncology nurses work with cancer patients across a continuum of care that ranges from initial diagnosis, aggressive treatment, cure, remission, and end of life care. These nurses bear witness to patients' trauma and suffering (be it physical or emotional) at all phases of the disease, and are ultimately responsible for providing holistic care for their patients and supporting their families throughout the process. ${ }^{[26]}$ Holistic nursing care embraces all aspects of patients including their physical, psychological, social, cultural, and spiritual needs, as well as the needs of the patients' families and support systems. More so, communicating bad news in terms of helping patients understand diagnosis, treatment failure; and ethical decision making are part of the nurses' responsibilities. This care often occurs repeatedly over an extended length of time and bonds are formed with patients. ${ }^{[27]}$ Despite providing the best care to these patients, nurse caregivers find that cancer can often continue to progress and the nurse- patient relationship can end with the patient's death. Some deaths may be expected and supported by hospice services, while many others may not be expected and are the result of traumatic emergency events related to their disease. This can be extremely stressful for oncology nurses, as they tend to empathize with patients' losses, resulting in a personal sense of futility or failure in their care. ${ }^{[23]}$ When a patient dies, the nurse also grieves with the family and supports them emotionally. ${ }^{[28]}$ Based on the foregoing, the oncology nurse witnesses profound suffering of patients which brings with it weariness, leaving the nurse in certain degrees of emotional distress. This is evident in moderate to high levels of compassion fatigue found from various studies that investigated prevalence of compassion fatigue among cancer nurses. ${ }^{[22,23,29,30]}$

Evidence from literatures suggest that susceptibility to compassion fatigues greatly depends on individual characteristics of the nurse and some institutional factors. Novice nurses have been found to be more susceptible to compassion fatigue because they are still struggling to adapt roles worsened by exposure to trauma. ${ }^{[31,32]}$ Similarly, studies have shown an inverse relationship between compassion fatigue, knowledge and skill. ${ }^{[33]}$ Lack of knowledge stems from a lack of education on coping skills. Craigie et al. also found that individuals with trait negative affect exhibit negative emotions when experiencing challenges and therefore have higher rates of compassion fatigue. ${ }^{[34]}$ On the other hand, lack of managerial support, organizational commitment, work load, group cohesion, work engagement and conflicting expectations of the nurse are some of the organizational factors that contribute to development of compassion fatigue. [32, 33, 35, 36]

According to Mescia and Gentry, compassion fatigue generally occurs as a spectrum beginning from the zealot stage where the caregiver is full of enthusiasm and energy to serve to the irritability which is characterized by loss of concentration and distancing oneself from others. ${ }^{[37]}$ At the next stage which is withdrawal, the caregiver loses patience, exhaustion is more frequent and enthusiasm disappears. In the final stage which is the zombie or quitting stage, there is full blown frustration, hopelessness and anger. From the stage, the caregiver can either spring on to action to combat compassion or become overwhelmed with negative emotions. ${ }^{[37]}$

To identify compassion fatigue in caregivers, some instruments which examine certain characteristics of the caregivers are utilized. The commonest self-test for assessing compassion satisfaction and the risk of compassion fatigue is the professional quality of life scale by Beth Hudnall Stamm. ${ }^{[38]}$ It is a 30-question, five-point Likert scale test with subscales for compassion satisfaction, burnout and secondary traumatic stress. For this scale, compassion fatigue comprises of burnout and secondary traumatic stress. Other tools are the compassion fatigue scale and secondary traumatic stress scale. $[21,40]$

Compassion fatigue comes with variety of signs and symptoms that may be similar to other syndromes such as burnout because of the ambiguity of the term. Symptoms are concealed and may have insidious onset leading to late detection. 
Warning signs may be behavioural, emotional or physical. Panos noted that behavioural signs include feeling estranged from others, insomnia, preoccupied with patients, a sense of worthlessness and resentment with work. ${ }^{[40]}$ Emotionally, there is a reduced ability to feel sympathy or empathize with patients as a result of distancing oneself from patients' trauma, increased anxiety and guilt. ${ }^{[41]}$ Physical warning signs include: exhaustion and physical fatigue, headaches, insomnia, increased susceptibility to illness, hypochondria, palpitations, sore back and neck, irritable bowel or GI distress lack of energy, loss of endurance, loss of strength, proneness to accidents, weariness, headaches, digestive problems, muscle tension and cardiac symptoms etc. ${ }^{[\mathbf{9}, \mathbf{4 2}, \mathbf{4 3}]}$ According to Radziewicz, nurses experiencing compassion fatigue may have doubt concerning value systems and beliefs, they may begin to think of making major life changes such as switching jobs, they may even become angry with God. ${ }^{[44]}$ Furthermore, compassion fatigue have consequences for both individual nurses and the organizations they work for. Compassion fatigue can be the cause for health care workers exiting the profession; it could also result to lessened career self-worth which could result in drug use. ${ }^{[9]}$ On organizations, the effects of compassion fatigue experienced by health care workers include an increase in absenteeism and staff turnover, decrease in quality of patient care, decreased patient satisfaction, and decrease in patient safety as a result of medication errors and poor record keeping. ${ }^{[29]}$ There could also be difficulty recruiting and retaining staff. ${ }^{[29]}$ Furthermore, an organisation may lose its reputation if patient care is compromised due to staff being unable to cope with the pressure of work. ${ }^{\text {[22] }}$

\section{STRATEGIES FOR LIMITING THE EMOTIONAL COST OF CARING BY INDIVIDUAL NURSES, NURSE MANAGERS AND INSTITUTIONS}

Self-compassion and self-kindness are means through which oncology nurses can deal with compassion fatigue. This means an inward direction of compassion to oneself as the object of compassion. Positive psychological traits such as emotional intelligence and resilience are associated self-compassion. ${ }^{[45]}$ It has also been found that high levels of self-compassion is associated with lower levels of compassion fatigue. ${ }^{[46]}$ Ways to demonstrate self-compassion include refusing to be a victim despite work challenges, remembering to laugh and engaging in self-care. American Holistic Nurses association emphasised the importance of caring for oneself physically, emotionally, mentally and spiritually while caring for cancer patients. ${ }^{[47]}$ Lawson and Venart found travels, vacation, hobbies, socializing and limiting case load as beneficial self-care strategies. ${ }^{[48]}$ Jones \& Williams added nutrition as a self-care strategy. ${ }^{[19]}$ Because it is understood nurses may make unhealthy choice of food in order to save time, good nutrition should be adopted as it is essential to help nurses stay healthy and feel good. Also, Kilian noted quality time with friends and family, exercise and spirituality as the beneficial self-help strategies among therapists. ${ }^{[49]}$ Adequate rest, exercise and healthy sleep patterns have been found to be helpful in preventing compassion fatigue. ${ }^{[\mathbf{5 0}, \mathbf{5 1}]}$ Journaling is another means of discharging emotions, attaining self-awareness and managing stress. ${ }^{[52]}$ While using intrinsic resources to manage emotions arising from care of cancer patients, extrinsic support from others is also helpful. Depippo in a study to determine self-care strategies of addiction workers also found that most participants depended on supervisors, co-workers and colleagues for guidance and support in emotional distress. [53] It enables the individual to process trauma materials, gain suggestions and get validation about clinical directions. Supervision also permits managers to form close bonds with subordinates so as to identify their difficulties and anxieties. ${ }^{[53]}$ Depipo also found that spending time with people other than colleagues was helpful in dealing with compassion fatigue. ${ }^{\left[{ }^{[53}\right]}$ Furthermore, it is important that nurses set firm emotional boundaries to protect themselves because compassion fatigue has not only physical and mental implications but also legal and ethical implications. Boundary setting is an ethical obligation for professionals. ${ }^{[54]}$ Nurses must learn how to remain compassionate and supportive of others without becoming intensely involved emotionally. Setting professional boundaries keeps the patients as well as the nurse safe by protecting them from certain distressing emotions. ${ }^{[51]}$ The nurse maintains connection with patients while making efforts to distance self so as not to be overwhelmed. Boundary setting involves employers and this is achieved by avoiding work-related calls after working hours, keeping caseload low and leaving work matters at work. ${ }^{[53]}$

Asides the effort of individual nurses, waging a profitable war on compassion fatigue will not be feasible without the contributions of nurse managers and institutions. Acknowledging that grief exists has been noted as the first important step in reducing compassion fatigue. ${ }^{[9]}$ When hiring new staff for cancer centres, the nurse manager or interviewer should make it clear that emotional distress will most likely occur but that options to manage the distress are available. Nurse Managers should appreciate nurses' contributions to patients' wellbeing and to the organization from time to time, this reduces a feeling of futility of efforts especially in cases where death was the outcome. ${ }^{[12]}$ Formal education or orientation courses required for oncology nurses should include education on communication skills, conflict resolution, ethical issues and selfcare. Oncology nurses can also gain proficiency in the nursing care of the dying before starting work. This will help them to optimize their experiences with the dying patients and their families. ${ }^{[55]}$ Continuing education programs with emphasis on compassion fatigue and coping skills is important in oncology units for resilience and coping. ${ }^{\text {[9] }}$ Nurse Managers should foster an environment where team work is promoted and positive working relationships enabled. ${ }^{[56]}$ This will enable the development of a supportive peer network that makes it easy for nurses to confide in colleagues and seek help early when warning signs of compassion fatigue are noticed. ${ }^{[13]}$ When nurses work together, they share in the outcome of patient care so that it is not individualized especially in cases of death. One nurse is not left to grieve, but communal grieving which may reduce the emotional impact on individual nurses. Utilizing debriefing sessions provide an avenue for emotional venting and help staff to recognize that they are not alone. It should focus on events, actions, perceptions, feelings and 
processing events rather than laying of complaints. ${ }^{[12]}$ Additionally, Staff members should always be reminded of the importance of self-care activities and the way to maximise opportunities for caring for self especially when observed to be exhibiting behaviours that show poor self-care. ${ }^{[2]}$

On the part of organizations, hospital managers should ensure that there is an on-site counselling by a clinical psychologist, therapist, counsellor, social worker or chaplain trained in the provision of emotional and spiritual support for healthcare providers experiencing real or potential compassion fatigue. ${ }^{[9]}$ Spaces should be provided on the oncology units for decompression relaxation, engaging in mindfulness and reflecting on practice. These spaces can be in form of lounges with cafeteria, chapels, and art rooms. ${ }^{[2]}$

\section{IMPLICATION FOR CANCER NURSING}

Compassion fatigue has been recognized as a prevalent condition in nurses caring for patients with cancer because of the physical, emotional and psychological toll cancer takes on them. Cancer nurses must be aware of the effects of caring on their ability to nurture and learn to develop resiliency skills that will enable them to manage with the daily stressors in an effective manner. Nurse Managers should also support subordinates by creating opportunities for sharing emotions and providing emotional support as necessary. They can engage in lobbying to improve the workplace experience of nurses. Compassion fatigue test could be given to nurses from time to time to assess their ability to cope with work challenges. In the same vein, nurse educators should ensure that student nurses are given due preparations for the inevitable challenges in the work environment, they should therefore be armed with the necessary skills that will help them cope with the demands of caring for patients with cancer. Additionally, ongoing continuing education is important for reinforcement of the strategies to cope with emotional stress in order to prevent compassion fatigue. For nurse researchers, studies on prevalence or lived experiences with compassion fatigue should be done settings to identify peculiarities with each setting and proffer solutions amenable to the each setting.

\section{CONCLUSION}

Oncology nurses are at the epicentre of the cancer tragedy; laden with suffering, pain and loss which impact on the compassion ability of the nurse. Because it is essential that nurses should be healed so as to effect healing in the others, providing nurses with tools and opportunities for self-care is paramount for retaining compassion and effectively carrying out their roles. Cancer nurses should be aware of the symptoms of compassion fatigue and ways of creating professional boundaries in the nurse-patient relationship so they can balance work and home life. Managers and cancer nurses should provide assistance for colleagues experiencing compassion fatigue. Also, hospital organizations should provide training on coping strategies helpful in managing emotions generated by cancer care prior to employment and continue ongoing education while they work. Employee assistance programs which constitute interventions for treating compassion fatigue should regularly be available for oncology nurses experiencing symptoms. By these, cancer nurses are supported to care for cancer patients and they experience a reduced risk of compassion fatigue. In essence, for caregiving to be effective, the care giver must be cared for.

\section{RECOMMENDATIONS}

1. Hospital managers should make provisions for regular training of nurse-managers regarding identification and prevention of compassion fatigue

2. Nurse administrators in charge posting and rotation of nurses may consider personality types and emotional predisposition before posting to different units especially for areas known to evoke profound emotions such as oncology units, hospice, emergency units, intensive care units

3. Ward heads/managers should consider flexibility in scheduling nurses. Length of shift or hours of work should be such that permit adequate rest. Self-scheduling should be permitted if possible.

4. Hospital leadership should provide and ensure that facilities for relaxation are functional. Each unit should have a lounge with canteen services where break periods can be spent

5. Nurse managers should provide additional support for nurses at higher risk for compassion fatigue and possible duty rescheduling for nurses experiencing family issues to reduce the emotional burden on them.

6. Nurse Managers should always identify nurses need for any improvement in work place culture and lobby/negotiate for better working conditions if need be.

7. Curriculum for training nurses should include courses on compassion, compassion fatigue and self-care strategies for nurses working in emotion laden specialty areas such as oncology nursing

8. Nurse Managers should ensure that nurses are rotated for very severe cases of cancer so that only one nurse does not get overwhelmed with the patient's condition.

9. Hospital leaders should support professional development in form of certificate courses or degrees in oncology nursing that will improve nurses' skill because with improved skill, nurses experience less frustration at work. 


\section{REFERENCES}

1. International Agency for Research on Cancer (IARC). Latest global cancer data. WHO, 2018. https://www.who.int/cancer/PRGlobocanFinal.pdf

2. Nolte AGW, Downing C, Temane A. \& Hastings-Tolsma M. Compassion fatigue in nurses: A metasynthesis. Journal of Clinical Nursing; 2017; 26(23-24);4364-4378.

3. Adereti SC, Olaogun AA, Olagunju EO, Afolabi KE. Paediatric patients' and primary care givers' perception of Nurse-caring Behaviours in South-western Nigeria. International Journal of Caring Sciences; 2014; $7(2)$.

4. Fieldman C, Kuyken W. Compassion fatigue in the landscape of suffering. Contemporary Budhism; $2011 ; 12(1) ; 143-155$.

5. Meyer A, Moran C. Fitzpatrick T, Ernst J, Komer A. Oncology Volunteers: The effect of a personal cancer history on compassion and psychological wellbeing. Clinical journal of oncology nursing; 2018; 22(4), 398-406.

6. Cocker F, Joss N. Compassion fatigue among emergency and community service workers: A systematic review. International journal of environmental research and public health; 2016; 13(6); 1-18.

7. Salmond E, Ames M, Kaimenski M, Watkins A, Holly, C. Experiences of Compassion Fatigue in Direct care Nurses. A Qualitative Systematic Review Protocol; 2017; 15(17).

8. Boyle DA. Occupational stress in oncology nurse caregiving: caring for ourselves. Clinical journal of oncology nursing; 2018; 19(5); 499.

9. Boyle DA. Countering compassion fatigue. A requisite nursing agenda. Online Journal of Issues in Nursing; 2011; 16(1); 2.

10. Vachon ML, Huggard PK, Huggard J. Reflections on occupational stress in palliative care nursing. In B.R. Ferrell, N. Coyle, and J. Paice (Eds.), Oxford textbook of palliative nursing; 2015; (4thed., pp. 969-986). Oxford University Press.

11. Figley CR. Compassion fatigue: Coping with secondary traumatic stress disorder in those who treat the traumatized; 1995. Brunner/Mazel.

12. Harris C, Quinn Griffin MT. Nursing on empty: compassion fatigue, signs, symptoms, and system interventions. Journal of Christian Nursing; 2015; 32(2), 80-87.

13. Coetzee S, Klopper HC. Compassion fatigue within nursing: A concept analysis. Nursing \& Health Sciences; 2010; 12(2).

14. Coetzee SK, Laschinger HK. Towards a comprehensive, theoretical model of compassion fatigue: An integrative literature review. Nursing and health sciences; 2017; 20(1); 4-15.

15. Fernando AT, Consedine NS. Beyond compassion fatigue: the transactional model of physician compassion. Journal of Pain and Symptom Management; 2014; 48(4); 289-98.

16. Valent P. Diagnosis and treatment of helper stresses, traumas, and illnesses. In Treating Compassion Fatigue; 2002. Brunner-Routledge.

17. Stamm HB. Professional quality of life: compassion satisfaction and compassion fatigue, version 5 ProQoL; 2010a.

18. Collins S, Long A. Too tired to care? The psychological effects of working with trauma. Journal of Psychiatric and Mental Health Nursing; 2003; 10; 17-27.

19. Jones P, Williams AM. Self-care: A guide for addiction professionals. Substance Abuse and Mental Health Services Administration; 2007. http://www.attcnetwork.org/userfiles/file/MidAtlantic/SelfCareGuide.pdf 20. Bell H. Strengths and secondary trauma in family violence work. Social Work; 2003; 48(4); 513-522.

21. Bride B E, Radey M, Figley CR. Measuring Compassion Fatigue. Clinical Social Work Journal; 2007; $35(3) ; 155-163$.

22. Gillepsie ME. Compassion fatigue and cancer nurses: a survey of cancer nurses in new Zealand (masters thesis).Eastern institute of technology, Taradale, New Zealand; 2013. https://repository.digitalnz.org/system/uploads/record/attachment/668/compassion_fatigue_and_cancer_nurses_ a_survey_of_new_zealand_nurses.

23. Potter P, Deshields T, Divanbeigi J, Berger J, Cpriano D, Norris L, Olsen S. Compassion fatigue and burnout: prevalence among oncology nurses. Clinical journal of oncology nursing; 2010; 14(5), E56-E62.

24. Flarity K, Nash K, Jones W, Steinbruner D. Intervening to improve compassion fatigue resiliency in forensic nurses. Advanced Emergency Nursing Journal; 2016; 38(2); 147-156.

25. Coles TB. Compassion fatigue and burnout: history, definitions and assessment; 2017. https://www.vmdtoday.com/journals/vmd/2017/october2017/compassion-fatigue-and-burnout-historydefinitions-and-assessment? $\mathrm{p}=2$.

26. Marcial L, Brazina M, Diaz A, Jaramillo C, Marentes G, Mazmanian N. A brief article: is this the cost of caring? A student perspective on compassion fatigue. Dimensions of critical care nursing, 2013; 32(1); 18-21. 
27. Quinal L, Harford S, Rutledge DN. Secondary traumatic stress in oncology staff. Cancer nursing; 2009; 32(4);E1-7.

28. Hecktman HM. Stress in paediatric oncology nursing. Journal of paediatric oncology nursing; 2012; 29(6); 356-361.

29. Hooper C, Craig J, Janvrin, DR, Wetset MA \& Reimels E. Compassion satisfaction, burnout, and compassion fatigue among emergency nurses compared with nurses in other selected inpatient specialties. Journal of Emergency Nursing; 2010; 36(5); 420-7.

30. Yu H, Jiang A, Shen J. Prevalence and predictors of compassion fatigue, burnout and compassion satisfaction among oncology nurses: Across-sectional survey. International Journal of Nursing Studies; 2016; 57; 28-38.

31. Li A, Early SF, Mahrer NE, Klaristenfeld JL, Gold JI. Group cohesion and organizational commitment: Protective factors for nurse residents' job satisfaction compassion fatigue, compassion satisfaction, and burnout. Journal of Professional Nursing; 2014; 30(1); 89-99.

32. Hunsaker S, Chen HC, Maughan D, Heaston S. Factors that influence the development of compassion fatigue, burnout, and compassion satisfaction in emergency department nurses. Journal of Nursing Scholarship; 2015; 47(2), 186-194.

33. Sacco TL, Ciurzynski SM, Harvey ME, Ingersoll GL. Compassion satisfaction and compassion fatigue among critical care nurses. Critical Care Nurse; 2015; 35(4); 32-44.

34. Craigie M, Osseiran-Moisson R, Hemsworth D, Aoun S, Francis K, Brown J, . Rees C. The influence of trait-negative affect and compassion satisfaction on compassion fatigue in Australian nurses. Psychological Trauma: Theory, Research, Practice, and Policy; 2016; 8(1); 88-97.

35. Perez GK, Haime V, Jackson V, Chittenden E, Mehta DH, Park ER. Promoting resiliency among palliative care clinicians: Stressors, coping strategies, and training needs. Journal of Palliative Medicine; 2015; 18(4); 332-337

36. Mason VM, Leslie G, lark K, Lyons P, Walke E, Butler C, Griffin M. Compassion fatigue, moral distress, and work engagement in surgical intensive care unit trauma nurses. Dimensions of Critical Care Nursing; 2014; 33(4); 215-225.

37. Mescia ND, Gentry JE. Florida Center for Public Health Preparedness. Understanding compassion fatigue: Helping public health professionals and other front-line responders combat the occupational stressors and psychological injuries of bioterrorism defence for a strengthened public health response: course manual; 2004 www.fcphp.usf.edu/courses/content/ucf/ucf_manual.pdf. Published 2004

38. Stamm BH. The Concise Proqol Manual, 2nd ed.; Proqol.org; 2010b. Pocatello, ID, USA.

39. Gentry JE. Compassion Fatigue: A crucible of transformation. Journal of Trauma Practice; 2002; 1(3); 37-61.

40. Panos A. Understanding and preventing compassion fatigue - A handout for professionals; 2007. http://www.giftfromwithin.org/html/prvntcf.html

41. Vlack TV. Warning signs of vicarious trauma/ secondary traumatic stress and compassion fatigue; 2017 www.tendencyacademy,ca/category/featured.

42. Lombardo B, Eyre C. Compassion fatigue: a nurse's primer. Online Journal on Issues of Nursing; 2011; $16(1), 3$.

43. Wentzel D, Brysiewicz P. The consequence of caring too much: compassion fatigue and the trauma nurse. Journal of Emergency Nursing; 2014; 40 (1), 95-7.

44. Radziewicz, R. Self-care for the caregiver. Nursing clinics of North America; 2002; 36(4); 855-69.

45. Duarte J, Pinto-Gouveia J. The role of psychological factors in oncology nurses' burnout and compassion fatigue symptoms. European Journal of Oncology Nursing; 2017; 28, 114-121.

46. Upton KV. An investigation into compassion fatigue and self-compassion in acute medical care hospital nurses: a mixed method study. Journal of Compassionate health care; 2018; 5(7); 1-27.

47. American Holistic Nurses Association. Nuture yourself; 2014 http://www.ahna.org/membership/member-advantage/self-care.

48. Lawson G, Venart B. Preventing Counselor Impairment: Vulnerability, Wellness, and Resilience, Article $53 ; 2005$.

49. Killian KD. Helping till it hurts? A multimethod study of compassion fatigue, burnout, and self-care in clinicians working with trauma survivors. Journal of Traumotology; 2008; 14(2), 32-44.

50. Houck D. Helping nurses cope with grief and compassion fatigue: an educational intervention. Clinical journal of oncology nursing; 2014; 18(4), 454-458.

51. Melvin CS. Historical review in understanding burnout, professional compassion fatigue and secondary traumatic disorder from a hospice and palliative care nursing perspective. Journal of hospice and palliative care nursing; 2015; 17(1); 66-72.

52. Dimitroff LJ, Silwoski L, O’Brien S, Nichols LW. Change your life through journaling- The benefits of journaling for registered nurse. Journal of nursing education and practice; 2016; 7(2), 90-98. 
53. DePippo AG. Compassion fatigue and self-care strategies among addiction professionals. A qualitative study (doctoral dissertation).university of South Florida; 2015. http://scholarcommons.usf.edu/etd/5677

54. American Counseling Association. ACA code of ethics; 2014. Alexandria, VA: Author.

55. Aycock N. Boyle D. Interventions to manage compassion fatigue in oncology nursing. Clinical Journal of oncology nursing; 2009; 13(2); 183-191.

56. Sorenson C, Bolick B, Wright K, Hamilton R. Understanding compassion fatigue in healthcare providers: A review of current literature. Journal of Nursing Scholarship; 2016; 48(5); 456- 465. 